\title{
NON-TARGET EFFECTS OF Dalaca pallens BLANCHARD CONTROL EXAMINED THROUGH PRINCIPAL RESPONSE CURVES: A GUILD APPROACH IN SOUTHERN CHILE
}

\author{
Luis Devotto ${ }^{1,2 *}$, Ernesto Cisternas ${ }^{1}$, Roberto Carrillo ${ }^{2}$, and Marcos Gerding ${ }^{1}$
}

\begin{abstract}
A B S T R A C T
The non-target effects of biological control are a complex matter requiring a multi-approach analysis. A fungal biopesticide is under research to control the larval stages of the ghost moth Dalaca pallens Blanchard (Lepidoptera: Hepialidae) in southern Chile. A field experiment was conducted to compare the effects of the biological control agent Beauveria bassiana (Balsamo) Vuillemin $\left(10^{12}\right.$ spores ha- $\left.{ }^{-1}\right)$ and the insecticide lambdacyhalothrin ( $7.5 \mathrm{~g}$ active ingredient $\left.\mathrm{ha}^{-1}\right)$ on non-target invertebrate species belonging to different guilds. The soil invertebrates were collected by using pitfall trapping and soil coring before and after spraying the biocontrol agent or the insecticide. Caught individuals were assigned to predator, herbivore or decomposer guilds and then a relatively new multivariate technique called principal response curves (PRC) was adopted to track the potential treatment effects over time in the abundance or activity of the non-target guilds. The products targeting $D$. pallens caused different effects on guilds: lambda-cyhalothrin decreased the activity-density of the predator guild but not herbivore or decomposer guilds, while the biological control agent caused no reduction in the activity-density of the three examined guilds. The negative effects of the insecticide were present from 1 to 60 days after treatment.
\end{abstract}

Key words: ghost moth, entomopathogen, biopesticide, Beauveria bassiana, Lepidoptera, Hepialidae

\section{INTRODUCTION}

The non-target effects of biological control are a growing issue that has motivated debate in recent years (Simberloff and Stiling, 1996; Louda et al., 2003). The evaluation of these unintended effects is complex and a key component of any species introduction or augmentation program. In consequence, methodologies are urgently needed as restrictions to importation/ movement of biological control agents become more stringent (Solomon and Giesy, 2001).

Several approaches have been used to accomplish this goal, from measurement of changes in total diversity to species-by-species testing of susceptibility to the biological control agent. The single species approach has a long tradition in the non-target literature (Howarth, 1991), and often is the starting point of the research. On the other hand, the total diversity approach is also widely used in the field of biocontrol (Duelli et al., 1999). In addition, a third approach, the guilds, has been proposed as a useful conceptual and operative tool that can help to better predict the performance and the ecological consequences of biocontrol (Ehler, 1992; Greenstone, 1999; Symondson et al., 2002).

After an experiment is carried out and data gathered, analysis is often limited by the non-normality of the data, the presence of many zero counts and other factors that make univariate standard statistics fail (van den Brink and ter Braak, 1999); these authors developed a technique based on ordination, known as principal response curves (PRCs), designed for

\footnotetext{
${ }^{1}$ Instituto de Investigaciones Agropecuarias, Centro Regional de Investigación Quilamapu, Casilla 426, Chillán, Chile. E-mail: ldevotto@inia.cl_* Corresponding author.

${ }^{2}$ Universidad Austral de Chile, Facultad de Ciencias Agrarias, Casilla 567, Valdivia, Chile. Received: 4 September 2007. Accepted: 18 December 2007.
} 
mesocosm experiments that involve many species and sampling dates. This technique was adopted to analyze this experimental data because it allows for overcoming the problems arising from non-normal and multivariate data sets. The PRCs have recently been extended to terrestrial environments to assess the impact of transgenic crops (Candolfi et al., 2004; Naranjo, 2005; Dively, 2005; Torres and Ruberson, 2005; 2007), chemical contaminants (Smit et al., 2002) and management regimes (Pernin et al., 2006) on invertebrate assemblages. As far as we know, only the studies of Naranjo et al. (2004) and Naranjo and Akey (2005) have addressed the side-effects of insecticides using this method, but it has not been used for the assessment of biological control agents.

A new biopesticide based on the fungus Beauveria bassiana Balsamo (Vuillemin) has been developed by the National Agricultural Research Institute (INIA), Ministry of Agriculture, Chile, against Dalaca pallens Blanchard (Lep. Hepialidae), which has caused similar mortality levels on the pest as pyrethroid lambdacyhalothrin (Cisternas et al., 2003). The selected strain has proven to be more environment-friendly than lambda-cyhalotrhin at the species (Devotto et al., 2007a) and at the community level (Devotto et al., 2007b), but it is necessary to evaluate both at intermediate levels, such as guilds. The aim of this study was to use multivariate statistics to analyze the effects of the entomopathogenic fungus Beauveria bassiana strain QU-B931 on the activity-density of predator, herbivore and decomposer guilds, and to compare these effects to those caused by the standard chemical lambda-cyhalothrin.

\section{MATERIALS AND METHODS}

\section{Procedures}

A detailed description of the site and environmental data has been given by Devotto et al. (2007a; 2007b). The site was located in the Experimental Station, Universidad Austral de Chile (39 $47^{\circ}$ S, $73^{\circ} 13^{\prime}$ $\mathrm{W})$, in a naturalized pasture comprised primarily of Lolium perenne L. and Holcus lanatus L. A single application of B. bassiana strain QU-B931 suspended in water, in a dose equivalent to $10^{12}$ spores $\mathrm{ha}^{-1}$, or the pyrethroid lambda-cyhalothrin (alpha-cyano-3phenoxybenzyl 3-(2-chloro-3,3,3-trifluoropropenyl)2,2-dimethylcyclopropanecarboxylate; $7.5 \mathrm{~g}$ a.i. $\mathrm{ha}^{-1}$ ) was sprayed on 15 October 2003 to $30 \times 30 \mathrm{~m}$ open plots established in the pastures. A water treatment was included as a control.
Two techniques were used to sample the invertebrate fauna: pitfall trapping (Greenslade, 1964) and TullgrenBerlese funnel extractions of soil cores (Krantz, 1978). Twelve traps were placed in the center of each plot for 4-day periods (one day before spraying and 1,30, and 60 days after spraying). Thirty soil cores were extracted randomly from each plot, one day before and 30 days after spraying. Because many factors aside from abundance influence pitfall trap captures, the term "activity-density" was adopted, following Thiele (1977), to record and present the results.

\section{Invertebrate identification}

Specimens were stored in $70 \%$ ethanol, and sorted under microscope; identification was performed following Artigas (1994), CSIRO (1991) and compared to a reference collection identified by Dr. Roberto Carrillo (Department of Plant Pathology, Universidad Austral de Chile). Some specimens were not identified at the species level, thus the terms "taxa" and "species" are used interchangeably in this paper. Voucher specimens were held in the Entomology Laboratory, Universidad Austral de Chile. Taxa belonging to the invertebrate assemblage of pastures were assigned to guilds based on Chilean literature and morphology, especially mouth parts. Predators sampled by pitfall trapping and soil coring were analyzed separately. Earlier studies conducted in the same field were the main source to assign taxa to the respective guild. These studies included monthly sampling of carabids (Zelada, 1998), gut content and exclusion experiments, conducted in different years and seasons (Carrillo, R., Universidad Austral de Chile, unpublished data).

\section{Statistics and data analysis}

A completely randomized design with four replicates was used. Principal response curves (PRC) were used to analyze the time and treatment-dependent multivariate response of selected guilds (van den Brink and ter Braak, 1999). The method summarizes all the changes in activity-density of the species belonging to the same assemblage simultaneously, and the principal response, a weighted sum of the abundances of the taxa, is expressed as a canonical coefficient and reflects the behavior of the treated communities relative to the untreated control (Dively, 2005).

Monte-Carlo (departures from the zero control line) permutation tests (van den Brink and ter Braak, 1999) were used to test the significance of treatment effects at each sampling date (1999 permutations). The partial redundancy analysis and the Monte-Carlo (MC) tests 
were performed on CANOCO software version 4.53 (ter Braak and Smilauer, 1998). Input data were $\log (\mathrm{x}+1)$ transformed for analysis. CANOCO outputs were used to calculate the PRCs in a spreadsheet using the formula:

$\mathrm{C}_{\mathrm{dt}}=(\mathrm{TAU} \times \mathrm{Regr}: \mathrm{AX} 1) / \mathrm{SD}$

where $\mathrm{C}_{\mathrm{dt}}=$ standardized canonical coefficients; TAU = total standard deviation of the species data; Regr:AX1 = regression/canonical coefficients for standardized variables; and SD = standard deviations of environmental variables. The obtained standardized canonical coefficients were used to draw up the lefthand columns of Figures 1 to 4 .

\section{RESULTS}

Over 4111 specimens were identified. The most important taxa were the carabid beetles $(42 \%)$, oribatid mites $(20 \%)$, gnaphosid spiders (16\%) and curculionid weevils (8\%). The remaining taxa accounted for $14 \%$. In terms of ecological functionality, $61 \%$ of the invertebrates were predators, $11 \%$ herbivores and $28 \%$ decomposers.

\section{Predator guild}

The pitfall predator guild was composed of two spider families (Lycosidae and Gnaphosidae) and 11 species of carabid beetles: Mimodromites cyaneus (Dejean), Trechisibus angularis Jeannel, Calosoma vagans
(Dejean), Metius flavipes (Dejean), Parhypates sp., Trirammatus unistriatus (Dejean), Allendia chilensis (Dejean), Argutoridius chilensis (Dejean), Ceroglossus chilensis Eschscholtz, Ferionomorpha aerea (Dejean), and Ferionomorpha nebroides (Curtis).

PRCs of the predator guild determined by pitfall trapping are shown in Figure 1. The first PRC was significant and explained $51.7 \%$ of the variance due to the treatment regime (Table 1). The second PRC would explain an additional $25.2 \%$ of the variance, but it was not significant $(\mathrm{P}=0.10)$. The first $\mathrm{PRC}$ showed non-significant variations present in the pre-treatment period, and significant deviations from the control in the insecticide plots occurred in the three post-application sampling dates.

More detailed information about the significance of treatment effects was gained by performing the MC permutation tests individually for each sampling date. The pre-treatment predator guild did not differ between biocontrol treatment and control plots (Table 2). One day after application of spores or insecticide, the predator guild activity decreased in the insecticide plots compared to the control plots $(\mathrm{P}=0.02)$, while the response curve for the $B$. bassiana plots fluctuated close to the zero line of the control, indicating no significant $(\mathrm{P}=0.68)$ changes in guild activity density. Date by date contrasts indicated that this pattern was present from days 1 through 60, thus the predator guild did

\begin{tabular}{ll} 
& Weights $\left(\mathrm{b}_{\mathrm{k}}\right)$ \\
\hline 2.74 & Ferionomorpha nebroides \\
1.79 & Ferionomorpha aerea \\
1.35 & Lycosidae \\
0.48 & Gnaphosidae \\
0.27 & Ceroglossus chilensis \\
0.27 & Argutoridius chilensis \\
0.22 & Allendia chilensis \\
0.20 & Trirammatus unistriatus \\
0.09 & Parhypates sp. \\
0.09 & Calosoma vagans \\
0.09 & Metius flavipes \\
0.05 & Trechisibus angularis \\
0.02 & Mymodromites cynaeus \\
\hline
\end{tabular}

2.74 Ferionomorpha nebroides

1.79 Ferionomorpha aerea

1.35 Lycosidae

0.48 Gnaphosidae

0.27 Ceroglossus chilensis

0.27 Argutoridius chilensis

0.22 Allendia chilensis

0.20 Trirammatus unistriatus

0.09 Parhypates sp.

0.09 Calosoma vagans

0.05 Trechisibus angularis

0.02 Mymodromites cynaeus

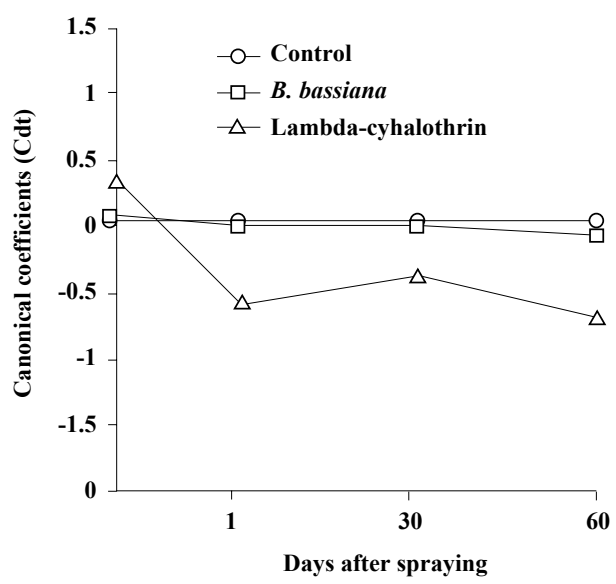

Figure 1. Principal response curve (PRC) for the predator guild from pitfall trapping, indicating the effects of a single spraying of Beauveria bassiana or lambda-cyhalothrin, compared to the control. Values deviating from the reference value of zero indicate treatment effects. Weights (right) indicate the affinity of the taxon to the PRC trend. 
Table 1. Variance partitioning of tested data sets. Significance level of the Principal Response Curves (PRC) is indicated in brackets (Monte-Carlo permutation tests, 1999 permutations).

\begin{tabular}{lcccccc}
\hline \multirow{2}{*}{ Data set } & \multicolumn{2}{c}{$\begin{array}{c}\text { Variance accounted for } \\
\text { by }\end{array}$} & & \multicolumn{2}{c}{$\begin{array}{c}\text { Variance explained by } \\
\text { treatment regime captured by }\end{array}$} \\
\cline { 2 - 3 } & Time & Treatment & & First PRC & Second PRC \\
\cline { 2 - 3 } & 42.4 & 18.5 & & $51.7(\mathrm{p}=0.01)$ & $25.2(\mathrm{p}=0.10)$ \\
Predator guild (pitfall trapping) & 33.0 & 28.1 & & $86.6(\mathrm{p}<0.01)$ & $11.1(\mathrm{p}=0.59)$ \\
Predator guild II (soil coring) & 26.8 & 14.1 & & $47.1(\mathrm{p}=0.79)$ & $36.5(\mathrm{p}=0.73)$ \\
Herbivore guild & 14.4 & 8.9 & & $76.5(\mathrm{p}=0.77)$ & $14.5(\mathrm{p}=0.99)$ \\
Decomposer guild & & & & &
\end{tabular}

Table 2. Significance level of treatment effects on the predator guild obtained by pitfall trapping, according to Monte-Carlo permutation tests, 1999 permutations.

\begin{tabular}{lcccc}
\hline & Before & \multicolumn{3}{c}{ Days after treatment } \\
\cline { 3 - 5 } & treatment & $\mathbf{1}$ & $\mathbf{3 0}$ & $\mathbf{6 0}$ \\
\hline Control vs. Beauveria bassiana & $\mathrm{P}>0.16$ & $\mathrm{P}>0.88$ & $\mathrm{P}>0.62$ & $\mathrm{P}>0.34$ \\
Control vs. lambda-cyhalothrin & $\mathrm{P}>0.10$ & $\mathrm{P}=0.02$ & $\mathrm{P}=0.02$ & $\mathrm{P}=0.05$ \\
B. bassiana vs. lambda-cyhalothrin & $\mathrm{P}>0.76$ & $\mathrm{P}=0.02$ & $\mathrm{P}=0.02$ & $\mathrm{P}=0.10$ \\
\hline
\end{tabular}

not recover in the sampling period (Figure 1). Overall, the predator guild in the insecticide plots was reduced $49 \%$ after application of lambda-cyhalothrin, while the predator activity-density was reduced $19 \%$ in the B. bassiana plots, compared to the control. However, only the lambda-cyhalothrin decrease was statistically significant.

For individual responses, the species' weights were recorded, as they denote the relative contributions to the PRC (strength of the response of each taxon). Taxa with high positive weights follow the same pattern as the PRC, whereas taxa with negative values behave contrarily to the PRC (van den Brink and ter Braak, 1998; 1999). The weighted scores for each taxon were ranked in Figure 1 (right). Main contributors to the negative impact observed in the insecticide treatment were $F$. aerea, F. nebroides, Lycosidae and Gnaphosidae.

On the other hand, the soil coring predator guild comprised six taxa: the spider families Gnaphosidae and Lycosidae, the rove beetle family Staphylinidae, the earwig Forficula sp., and the taxa Carabidae (larvae and adults). Carabid adults were pooled because they were present in low numbers. Carabidae larvae were treated as separated taxon because they were not unequivocally assigned to any species. The predator assemblage extracted from soil cores was very similar to that revealed by pitfall trapping. The only taxon presents in the soil cores but not in pitfall trapping was the rove beetle family Staphilinidae.
The first PRC was significant $(\mathrm{P}<0.01)$ and explained $87 \%$ of the variance due to the treatment regime (Table 1). The second PRC explained an additional $11 \%$ of the variance, but it was not significant (P $=0.59)$. No differences in the treated and control plots were present before spraying. Thirty days after spraying the predator guild was reduced by the lambda-cyhalothrin treatment (Table 3), on the basis of the MC permutation tests $(p=0.02)$, while the predator guild was similar between the B. bassiana treatment and the control $(\mathrm{P}=0.77)$. Predators as a whole were reduced by $74 \%$ in the insecticide plots compared to the control plots

Table 3. Significance level of treatment effects on the predator guild from soil cores and the nontarget herbivore guild (30 days after spraying) according to Monte-Carlo permutation tests, 1999 permutations.

\begin{tabular}{lc}
\hline Predator guild (pitfall trapping) & $\begin{array}{c}\text { 30 days } \\
\text { after } \\
\text { spraying }\end{array}$ \\
\hline Control vs. Beauveria bassiana & $\mathrm{P}=0.77$ \\
Control vs. lambda-cyhalothrin & $\mathrm{P}=0.02$ \\
B. bassiana vs. lambda-cyhalothrin & $\mathrm{P}=0.02$ \\
Non-target herbivore guild & \\
Control vs. B. bassiana & $\mathrm{P}=0.79$ \\
Control vs lambda-cyhalothrin & $\mathrm{P}=0.27$ \\
B. bassiana vs. lambda-cyhalothrin & $\mathrm{P}=0.80$ \\
\hline
\end{tabular}


(Figure 2B). The weighted scores for each taxon are shown in the right-hand column of Figure 2B. Main contributors to the adverse effects of lambdacyhalothrin were carabid adults, Gnaphosidae spiders and carabid larvae.

\section{Herbivore guild}

This guild comprised herbivore taxa sampled through soil coring and included eight taxa: the Argentine ryegrass weevil Listronotus bonariensis Kuschel, the diptera Tipula apterogyne Philippi, the families Elateridae, Noctuidae, Cantharidae, Curculionidae (larvae), the weevil Apion sp., and other Coleoptera. The herbivore guild measured by soil cores sampling consisted primarily of weevils (78\%), including Apion sp. (34\%), L. bonariensis (25\%) and curculionid larvae (20\%). Following in abundance were Cantharidae
$(6 \%)$ and other Coleoptera (12\%); the remaining taxa accounted for less than $2 \%$ of the total.

The first PRC captured $47 \%$ of the variance explained by the treatment regime, but this result was not significant $(P=0.79$, Table 1$)$. The herbivore guild in the pre-treatment sampling date was similar between treatments (Figure 2A). Thirty days after treatment, no significant effects of treatments on herbivore guild abundance were detected, on the basis of the MC permutation tests (Table 3 ).

\section{Decomposer guild}

This guild comprised four taxa sampled through soil coring, and four other taxa: earthworms (Lumbricidae), larvae of the Stratiomyidae family, the Oribatida mites and Coleoptera.

\section{A. Herbivore guild}

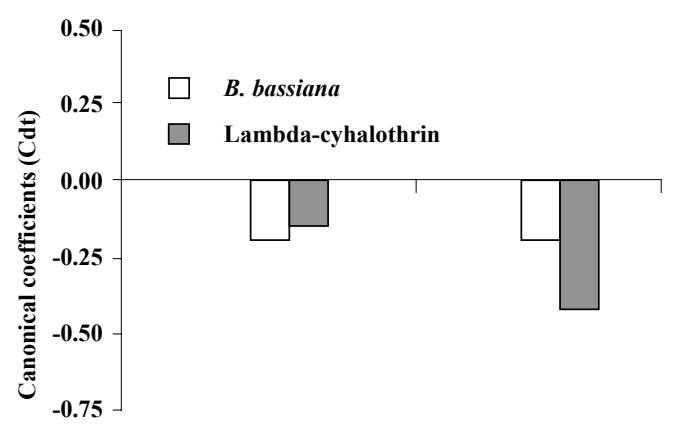

\begin{tabular}{l}
\multicolumn{1}{c}{ Weights $\left(\mathrm{b}_{\mathbf{k}}\right)$} \\
\hline 2.40 Listronotus sp. \\
$\mathbf{1 . 1 2}$ Tipula sp. \\
$\mathbf{0 . 6 6}$ Elateridae \\
$\mathbf{0 . 6 3}$ Noctuidae \\
$\mathbf{0 . 3 3}$ Other Coleoptera \\
$\mathbf{0 . 2 1}$ Cantharidae \\
$\mathbf{- 0 . 0 5}$ Curculionidae (larvae) \\
$\mathbf{- 0 . 0 8}$ Apion sp. \\
\hline
\end{tabular}

B. Predator guild

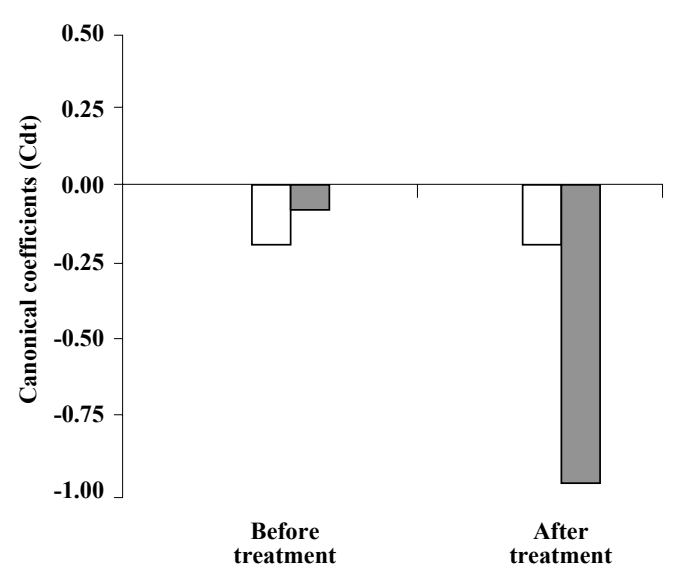

\begin{tabular}{ll} 
& Weights $\left(\mathbf{b}_{\mathbf{k}}\right)$ \\
\hline 1.45 & Carabidae (adults) \\
1.37 & Gnaphosidae \\
1.18 & Carabidae (larvae) \\
0.76 & Staphylinidae \\
$\mathbf{0 . 2 0}$ & Lycosidae \\
$\mathbf{0 . 0 3}$ & Forficula sp. \\
\hline
\end{tabular}

Figure 2. Principal response curve (PRC) for the herbivore and predator guild, indicating the effects of a single spraying of Beauveria bassiana or lambda-cyhalothrin. Weights (right) indicate the affinity of the taxon to the PRC trend. 


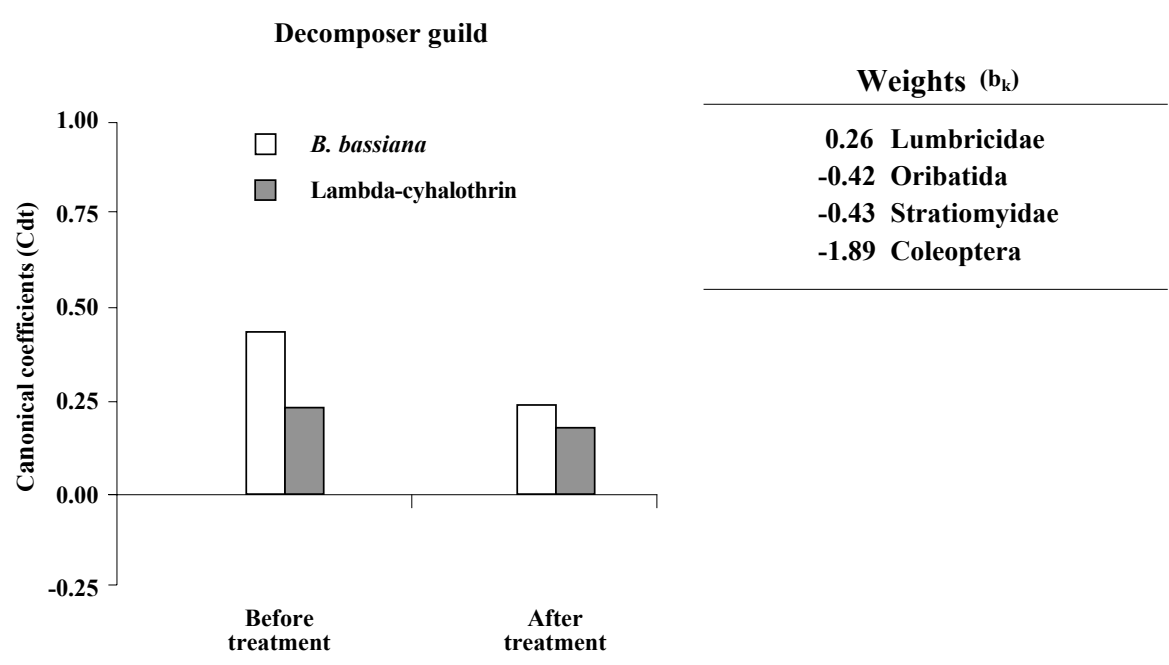

Figure 3. Principal response curve (PRC) for the decomposer guild, indicating the effects of a single spraying of Beauveria bassiana or lambda-cyhalothrin. Weights (right) indicate the affinity of the taxon to the PRC trend.

The first PRC captured $77 \%$ of the variance explained by the treatment regime, but this result was not significant $(\mathrm{P}=0.77$, Table 1$)$. The decomposer guild in the pretreatment sampling date was similar between treatments (Figure 3). Thirty days after treatment, no significant effects of treatments on herbivore guild abundance were detected, on the basis of the MC permutation tests.

\section{DISCUSSION}

Guilds responded differently to biocontrol and insecticide treatments. While the herbivore and decomposer guilds were not affected by treatments in the evaluation period, the predator guild was decreased by lambda-cyhalothrin insecticide at all post-treatment sampling dates. This response was consistent considering that abundance of predators extracted from soil cores followed the same pattern as predator activity-density from pitfall trapping.

The activity-density of the predator guild was numerically dominated by carabid beetles $(68 \%)$ and spiders (26\%). Negative effects of lambda-cyhalothrin on individually considered ground-dwelling predators have been widely reported in literature: some authors have characterized the effects as weak or transient (van den Berg et al., 1998; Wick and Freier, 2000; Candolfi et al., 2004), while others have reported strong or persistent effects (Dinter and Poehling, 1995). Some groups increased after lambda-cyhalothrin application (Wick and Freier, 2000).
In this study, lambda-cyhalothrin decreased the activitydensity of the predator guild by $49-74 \%$, depending on the sampling method (weighted mean $=54 \%$ ). This effect was almost constant throughout the experiment, as the magnitude of the decrease was similar at each sampling date.

The insecticide application reduced predator activitydensity as early as one day after treatment and it persisted through day 60 . This instantaneous effect could be attributed to the direct toxicological properties of lambda-cyhalothrin on predators, but the persistent decrease (at least 60 days) could be the result of more complex ecological mechanisms. Acute toxicity of lambda-cyhalothrin is not very likely after 60 days, especially if high temperatures and high organic matter content are present (Hill and Inaba, 1991). Therefore, mechanisms such as loss of habitat quality, lack of recruitment or depletion of prey cannot be ruled out as potential explanations. Following the classification scheme for pesticide effects on beneficial organisms suggested by Hassan (1992), the results of the lambdacyhalothrin treatment can be considered moderately harmful (51-75\% mortality or reduction on beneficial activity) and persistent (more than 30 days).

On the other hand, some B. bassiana strains have caused mortality on non-target predators at the laboratory level, but in general, field effects of this fungus are negligible or non-existent (Riedel and Steenberg, 1998; Jaronski et al., 1998; Wang et al., 2001), even at a dose as high as 
$10^{14}$ spores ha ${ }^{-1}$ in forests (Parker et al., 1997). Limited epizootic activity of $B$. bassiana on staphylinids was reported by Steenberg et al. (1995).

In this study, the $B$. bassiana isolate QU-B931 did not cause any significant adverse effects on the studied predator guilds, which agrees with several other studies that assessed different B. bassiana strains on selected species (Brinkman and Fuller, 1999; Wang et al., 2001; Ivie et al., 2002). In the biopesticide plots predators tended to decrease $19-27 \%$, depending on which data set was considered (weighted mean $=22 \%$ ), but these decreases were not significant at any date. In consequence, following the severity indexes for nontarget effects of biological control agents suggested by Lynch and Thomas (2000), our field results ranked 0 or 1 (less than $5 \%$ of mortality induced by infection, with no recorded significant population consequences). Therefore, isolate QU-B931 supposed a risk lower than other strains, such as B. bassiana ARSEF 2883 (James et al., 1995) or B. bassiana GHA (Jaronski et al., 1998). Persistence is short, and the spores are alive only in significant numbers less than one week on foliage, and less than 15 days in soil (Devotto et al., 2007b). Therefore, under field conditions non-target taxa were exposed only during a limited period of their life span. This short exposure period is relevant to consider this fungus as a safe biological control agent and could explain, at least partially, the lack of deleterious effects on non-target species. The inherent selective properties of $B$. bassiana also play an important role as an explanatory mechanism for the lack of adverse effects. In general, each strain has a narrow host range and infectivity decreases in heterologous hosts.

In recent years, gut content and exclusion experiments (Carrillo R., Universidad Austral de Chile, unpublished data) have given increasing evidence of the importance of ground-dwelling predators, particularly carabids, in Chilean pastures. Most of the studied carabids ( $T$. unistriatus, A. chilensis, F. aerea) feed on a range of prey, including animal (spiders, aphids, coleopterans, dipterans, lepidoptera larvae and hymenopterans; $65-80 \%$ of the content) and non-animal materials (pollen and fungi), confirming previous findings on the importance of carabids as natural pest control agents (Lövei and Sunderland, 1996).

Radio-nucleotide predation experiments conducted in other grassland systems have shown that spiders consume a high proportion of herbivore biomass, even higher than coleopteran predation (Riechert, 1999). Most spiders have long life cycles and generalist feeding habits, and therefore they have limited ability to exhibit densitydependent tracking of their prey (Riechert, 1999). On the other hand, spiders fit better to an equilibrium point model, which can be applied to relatively stable systems such as perennial pastures. Therefore, the substantial decrease in spider numbers could alter arthropod community dynamics, and it is unclear if other groups could perform the same function, considering they exert influence on prey dynamics through means different from predation, such as ceasing feeding by predator presence, foraging at less favorable sites and dropping off from host plants, with a final slowing of prey population growth (Riechert, 1999).

PCRs allowed easily following the trend of guilds over time. In a single-species analysis reported by Devotto et al. (2007b), only four taxa were affected by the chemical insecticide. In this study, the same four taxa are top ranked in the weights in Figure 1, showing the sensitivity of the multivariate approach, with the advantage of examining the trajectory of the whole assemblage at the same time. In addition, once the data are at hand, most researchers intuitively select the species to be submitted to univariate statistics (usually ANOVA) based on their numerical abundance or after drawing plots and detecting potential visible differences. Weights given by PRCs could be a means to do the selection process of species that deserve to be analyzed separately. The latter could be of great importance when the researcher deals with a myriad of taxa.

As shown in Table 1, time explained a large part of the variance in all the examined guilds, even more than the treatments. The PRCs allowed for separating the changes caused by time from those caused by treatment and consequently providing a more precise insight on the effects of the biopesticide and the insecticide. In this particular experiment, time was more important than treatment, which is not surprising because most of the insects are more active with increasing temperature. Once time effects are removed, the researcher can focuse only on treatment effects.

Results, especially for predators, warrant further investigation, as broad-spectrum insecticides will continue playing a role in $D$. pallens control. Anthropogenic pastures are relatively impoverished environments compared to more natural habitats, but they contribute to the biodiversity of southern Chilean ecosystems because of their extension and patchy landscape. 


\section{CONCLUSIONS}

The results of this study indicate that the use of $B$. bassiana spores in the field does not pose a significant hazard for any recorded non-target guild or taxon, while the use of a broad-spectrum insecticide (like lambda-cyhalothrin in this study) severely affected the predator assemblage. The ecological consequences of this disruption can not be foreseen in a short-term study, such as this one, but predator removal raises concerns about the provision of natural control of pests in these pastures.

\section{R E S U M E N}

Efectos no deseados del control de Dalaca pallens evaluados a través de curvas de respuesta principal: un enfoque de gremios en el sur de Chile. Luis Devotto $^{1,2 *}$, Ernesto Cisternas ${ }^{1}$, Roberto Carrillo ${ }^{2}, \mathrm{y}$ Marcos Gerding ${ }^{1}$. Los efectos no deseados del control biológico son una materia compleja que requiere un análisis desde enfoques múltiples. Se está investigando un bioplaguicida fúngico para controlar los estados larvarios de la polilla Dalaca pallens Blanchard (Lepidoptera: Hepialidae) en el sur de Chile. Se realizó un experimento de campo para comparar los efectos del agente de control biológico Beauveria bassiana (Balsamo) Vuillemin $\left(10^{12}\right.$ esporas ha $\left.^{-1}\right)$ y el insecticida lambda-cihalotrina (7,5 g i.a. ha $\left.{ }^{-1}\right)$ en invertebrados distintos a la plaga que pertenecen a diversos gremios. Los invertebrados se colectaron mediante trampas de caída y por extracción de cilindros de suelo antes y después de la aplicación del agente de control biológico o del insecticida. Los individuos capturados se clasificaron como depredadores, herbívoros, y descomponedores, y luego se usó una técnica estadística multivariada llamada curvas de respuesta principal (PRC) para evaluar los efectos potenciales de los tratamientos a través del tiempo, en la abundancia o actividad de los gremios. Los productos usados contra $D$. pallens produjeron efectos diferentes en los gremios: el insecticida disminuyó los depredadores pero no causó efectos en los herbívoros y en los descomponedores, mientras que el agente de control biológico no causó efectos negativos en ninguno de los tres gremios. Los efectos negativos del insecticida se manifestaron entre los días 1-60 del experimento.

Palabras clave: plagas de praderas, entomopatógeno, biopesticida, Lepidoptera, Hepialidae.

\section{ACKNOWLEDGMENTS}

The authors extend thanks to Leticia Silvestre (Instituto de Producción y Sanidad Vegetal, Universidad Austral, Chile) and Milenko Aguilera (Departamento de Zoología, Universidad de Concepción, Chile) for carabid and spider identification, respectively. We especially thank Paul van den Brink (Wageningen University, The Netherlands) for statistical advice, as well as the PRC analysis experience shared by several researchers. Funding came from Dirección de Investigación y Desarrollo, Universidad Austral de Chile, and MECESUP project AUS-9904.

\section{LITERATURE CITED}

Artigas, J. 1994. Entomología económica. Insectos de interés agrícola, forestal, médico y veterinario (nativos, introducidos y susceptibles de ser introducidos). Volume I. 1126 p. and Volume II. 943 p. Ediciones Universidad de Concepción, Concepción, Chile.

Brinkman, M.A., and B.W. Fuller. 1999. Influence of Beauveria bassiana strain GHA on nontarget rangeland arthropod population. Environ. Entomol. 28:863-867.

Candolfi, M.P., K. Brown, C. Grimm, B. Reber, and H. Schmidli. 2004. A faunistic approach to assess potential side-effects of genetically modified Bt-corn on nontarget arthropods under field conditions. Biocontrol Sci. Technol. 14:129-170.
Cisternas, E., M. Gerding, y A. France. 2003. Uso del hongo Beauveria bassiana ¿Cómo controlar la cuncunilla negra de las praderas sin usar insecticidas? Informativo Agropecuario BIOLECHE INIA-Quilamapu $\mathrm{N}^{\circ} 16$ p. 51-52.

CSIRO. 1991. The insects of Australia: a textbook for students and research workers. $2^{\text {nd }}$ ed. 1029 p. Melbourne University Press, Carlton, Australia.

Devotto, L., R. Carrillo, E. Cisternas, and M. Gerding. 2007a. Effects of lambda-cyhalothrin and Beauveria bassiana spores on abundance of Chilean soil surface predators, especially spiders and carabid beetles. Pedobiologia 51:65-73. 
Devotto, L., R. Carrillo, E. Cisternas, and M. Gerding. 2007b. Response of grassland soil arthropod community to biological and conventional control of a native moth: using Beauveria bassiana and lambda-cyhalothrin for Dalaca pallens (Lepidoptera: Hepialidae) suppression. Biocontrol 52:507-531.

Dinter, A., and H.M. Poehling. 1995. Side-effects of insecticides on two erigonid spider species. Entomol. Exp. Appl. 74:151-163.

Dively, G.P. 2005. Impact of transgenic VIP3a x Cry1 Ab lepidopteran-resistant field corn on the non target arthropod community. Environ. Entomol. 34:12671291.

Duelli, P., M.K. Obrist, and D.R. Schmatz. 1999. Biodiversity evaluation in agricultural landscapes: above-ground insects. Agric. Ecosyst. Environ. 74:33-64.

Ehler, L.E. 1992. Guild analysis in biological control. Environ. Entomol. 21:26-40.

Greenslade, P.J.M. 1964. Pitfall trapping as a method for studying populations of Carabidae (Coleoptera). J. Anim. Ecol. 33:301-310.

Greenstone, M.H. 1999. Spider predation: how and why we study it. J. Arachnol. 27:333-342.

Hassan, S.A. 1992. Guidelines for testing the effects of pesticides on beneficial organisms. Descriptions of the test methods. Bull. IOBC/WPRS 15:18-39.

Hill, B.D., and D.J. Inaba. 1991. Dissipation of lambdacyhalothrin on fallow vs. cropped soil. J. Agric. Food. Chem. 39:2282-2284.

Howarth, F.G. 1991. Environmental impacts of classical biological control. Annu. Rev. Entomol. 36:485509.

Ivie, M.A., D.A. Pollock, D.L. Gustafson, J. Rasolomandimby, L.L. Ivie, and W.D. Swearingena. 2002. Field-based evaluation of biopesticide impacts on native biodiversity: Malagasy Coleoptera and anti-locust entomopathogenic fungi. J. Econ. Entomol. 95:651-660.

Jaronski, S.T., J. Lord, J. Rosinska, C. Bradley, K. Hoelmer, G. Simmons, et al. 1998. Effect of a Beauveria bassiana-based mycoinsecticide on beneficial insects under field conditions. p. 651-656. Proceedings of the Brighton Crop Protection Conference, Pests and Diseases, Brighton. 16-19 Nov. 1998. Vol. 2. BCPC Publications, Farnham, UK.

Krantz, G.W. 1978. A manual of acarology. 509 p. $2^{\text {nd }}$ ed. Oregon State Univ. Bookstores Inc., Corvallis, Oregon, USA.

Louda, S.M., R.W. Pemberton, M.T. Johnson, and P.A. Follett. 2003. Nontarget effects - the Achilles' heel of biological control? Annu. Rev. Entomol. 48:365396.

Lövei, G.L., and K.D. Sunderland. 1996. Ecology and behavior of ground beetles (Coleoptera: Carabidae). Annu. Rev. Entomol. 41:231-256.
Lynch, L.D., and M.B. Thomas. 2000. Nontarget effects in the biocontrol of insects, nematodes and microbial agents: the evidence. Biocontrol 21:117-130.

Naranjo, S.E. 2005. Long-term assessment of the effects of transgenic Bt cotton on the abundance of nontarget arthropod natural enemies. Environ. Entomol. 34:1211-1223.

Naranjo, S.E., and D. Akey. 2005. Conservation of natural enemies in cotton: comparative selectivity of acetamiprid in the management of Bemisia tabaci. Pest Manage. Sci. 61:555-566.

Naranjo, S.E., P.C. Ellsworth, and J.R. Hagler. 2004. Conservation of natural enemies in cotton: Role of insect growth regulators for management of Bemisia tabaci. Biol. Control 30:52-72.

Parker, B.L., M. Skinner, W. Gouli, and M. Brownbridge. 1997. Impact of soil applications of Beauveria bassiana and Mariannaea sp. on nontarget forest arthropods. Biol. Control 8:203-206.

Pernin, C., J. Cortet, R. Joffre, J. Le Petit, and F. Torre. 2006. Sewage sludge effects on mesofauna and cork oak (Quercus suber L.) leaves decomposition in a Mediterranean forest firebreak. Environ. Qual. 35:2283-2292.

Riechert, S.E. 1999. The hows and whys of successful pest suppression by spiders: insights from case studies. J. Arachnol. 27:387-396.

Riedel, W., and T. Steenberg. 1998. Adult polyphagous coleopterans overwintering in cereal boundaries: winter mortality and susceptibility to the entomopathogenic fungus Beauveria bassiana. Biocontrol 43:175-188.

Simberloff, D., and P. Stiling. 1996. How risky is biological control? Ecology 77:1965-1974.

Smit, C.E., A.J. Schouten, P.J. van den Brink, M.L.P. van Esbroek, and L. Posthuma. 2002. Effects of zinc contamination on a natural nematode community in outdoor soil mesocosms. Arch. Environ. Contam. Toxicol. 42:205-216.

Solomon, K.R., and J.P. Giesy. 2001. Ecological risk assessment of pesticides. Hum. Ecol. Risk Assess. 7:493-495.

Symondson, W.O.C., K.D. Sunderland, and M.H. Greenstone. 2002. Can be generalist predators be effective biocontrol agents? Annu. Rev. Entomol. 47:561-594.

ter Braak, C.J.F., and P. Smilauer. 1998. CANOCO reference manual and user's guide to CANOCO for Windows. Microcomputer Power, Ithaca, New York, USA.

Thiele, H.U. 1977. Carabids beetles in their environments. A study on habitat selection by adaptations in physiology and behaviour. 369 p. Springer Verlag, Berlin, Germany.

Torres, J.B., and J.R. Ruberson. 2005. Canopy- and ground-dwelling predatory arthropods in Bt and nonBt cotton fields: patterns and mechanisms. Environ. Entomol. 34:1242-1256. 
Torres, J.B., and J.R. Ruberson. 2007. Abundance and diversity of ground-dwelling arthropods of pest management importance in commercial Bt and non-Bt cotton fields. Ann. Appl. Biol. 150:27-39.

van den Berg, H., K. Hassan, and M. Marzuki. 1998. Evaluation of pesticide effects on arthropod predator populations in soya bean in farmers' fields. Biocontrol Sci. Technol. 8:125-137.

van den Brink, P., and C.J.F. ter Braak. 1998. Multivariate analysis of stress in experimental ecosystems by Principal Curves and similarity analysis. Aquat. Ecol. 32:163-178.

van den Brink, P., and C.J.F. ter Braak. 1999. Principal response curves: analysis of time-dependent multivariate responses of biological community to stress. Environ. Toxicol. Chem. 18:138-148.
Wang, Y., R.L. Crocker, L.T. Wilson, G. Smart, X. Wei, W.T. Nailon, and P.P. Cobb. 2001. Effect of nematode and fungal treatments on nontarget turfgrass-inhabiting arthropod and nematode populations. Environ. Entomol. 30:196-203.

Wick, M., and B. Freier. 2000. Long-term effects of an insecticide application on non-target arthropods in winter wheat - a field study over 2 seasons. Anzeiger fur Schadlingskunde 73:61-69.

Zelada, S. 1998. Rol de la franja de bosque y de la pradera en la biología de especies de Carabidae (Coleoptera, Adephaga). 135 p. Mg. Sc. Dissertation. Universidad Metropolitana de Ciencias de la Educación, Santiago, Chile. 